$$
\text { CONF- } 980708--
$$

\title{
TEMPERATURE AND THERMAL STRESS DISTRIBUTIONS \\ FOR THE HFIR PERMANENT REFLECTOR \\ GENERATED BY NUCLEAR HEATING
}

\author{
S. J. Chang \\ Research Reactors Division \\ Oak Ridge National Laboratory \\ Oak Ridge, Tennessee \\ Presented at \\ ASME Pressure Vessel and Piping Conference \\ San Diego, California \\ July 26-30, 1998
}

"The submitted manuscript has been authored by a contractor of the U.S. Government under contract

No. DE-AC05-96OR22464. Accordingly, the U.S.

Government retains a nonexclusive, royalty-free license

to publish or reproduce the published form of this

contribution, or allow others to do so, for U.S.

Govemment purposes."

RECEIVED

JUN 10998

Q. STI

DISTRIBUTION OF TUIS DOCUMENT IS UNLIMITED

Prepared by the

Research Reactors Division

OAK RIDGE NATIONAL LABORATORY

Oak Ridge, Tennessee 37831

managed by

LOCKHEED MARTIN ENERGY RESEARCH CORP.

for the

U. S. DEPARTMENT OF ENERGY

under contract DE-AC05-96OR22464 


\section{DISCLAIMER}

This report was prepared as an account of work sponsored by an agency of the United States Government. Neither the United States Government nor any agency thereof, nor any of their employees, makes any warranty, express or implied, or assumes any legal liability or responsibility for the accuracy, completeness, or usefulness of any information, apparatus, product, or process disclosed, or represents that its use would not infringe privately owned rights. Reference herein to any specific commercial product, process, or service by trade name, trademark, manufacturer, or otherwise does not necessarily constitute or imply its endorsement, recommendation, or favoring by the United States Government or any agency thereof. The views and opinions of authors expressed herein do not necessarily state or reflect those of the United States Government or any agency thereof. 


\title{
TEMPERATURE AND THERMAL STRESS DISTRIBUTIONS FOR THE HFIR PERMANENT REFLECTOR GENERATED BY NUCLEAR HEATING'
}

\author{
Shih-Jung Chang \\ Senior Research Staff \\ Research Reactors Division \\ Oak Ridge National Laboratory \\ Oak Ridge, Tennessee 37831 \\ Phone/Fax: (423)574-9134/8576 \\ e-mail: sjc@ornl.gov
}

\begin{abstract}
The beryllium permanent reflector of the High Flux Isotope Reactor has the main functions for slowing down and reflecting the neutrons and housing the experimental facilities. The reflector is heated as a result of the nuclear reaction. Heat is removed mainly by the cooling water passing through the densely distributed coolant holes along the vertical or axial direction of the reflector. The reflector neutronic distribution and its heating rate are calculated by J. C. Gehin of the Oak Ridge National Laboratory by applying the Monte Carlo Code MCNP. The heat transfer boundary conditions along several reflector interfaces are estimated to remove additional heat from the reflector. The present paper is to report the calculation results of the temperature and the thermal stress distributions of the permanent reflector by applying the computer aided design code I-DEAS and the finite element code ABAQUS. The present calculation is to estimate the high stress areas as a result of the new beam tube cutouts along the horizontal mid-plane of the reflector of the recent reactor upgrade project. These high stresses were not able to be calculated in the preliminary design analysis in earlier 60's. The heat transfer boundary conditions are used in this redesigned calculation. The material constants and the acceptance criteria for the allowable stresses are mainly based on that assumed in the preliminary design report.
\end{abstract}

'Based on work performed at Oak Ridge National Laboratory, managed by Lockheed Martin Energy Research Corp., for the U.S. Department of Energy under contract DE-AC05-96OR22464. Accordingly, the U.S. government retains a nonexclusive, royalty-free license to publish or reproduce the published form of this contribution, or allow others to do so, for U.S. government purposes.

\section{INTRODUCTION}

The beryllium permanent reflector of the High Flux Isotope Reactor has the main functions for slowing down and reflecting the neutrons and housing the experimental facilities. The reflector is heated as a result of the nuclear reaction. Heat is removed mainly by the cooling water passing through the densely distributed coolant holes along the longitudinal direction of the reflector. Additional heat is removed from the reflector boundary through heat transfer boundary conditions. The reflector neutronic distribution and its heating rate are calculated by J. C. Gehin from the Computational Physics Division of the Oak Ridge National Laboratory by applying the Monte Carlo Code MCNP (ref. 1). The heat transfer boundary conditions along all the reflector surfaces are estimated by R. B. Rothrock. The present paper is to report the calculation results of the temperature and the thermal stress distributions of the redesigned permanent reflector by applying the computer aided design code I-DEAS and the finite element code ABAQUS. The present calculation is the first finite element solution for the reflector with the target holes and the beam tube cutouts. For the reflector redesgn program, the HFIR beam tubes 1 and 4 have been slightly modified and the beam tube 2 is to be enlarged. Also, the finite element results for the temperature and the stress distributions based on the preliminary HFIR reflector geometry are obtained and confirmed. To study the temperature and stress generated by the coolant holes, a simplified analytical estimate is made. The stress distribution along the cylindrical coolant hole for the redesigned geometry is approximately $11 \mathrm{ksi}$. that is approximately equal to the preliminary design result obtained by Hilvety (ref. 2). The preliminary design overestimated the heating rate but had more coolant holes. The material constants and the acceptance criteria for the allowable stresses used in the redesigned reflector are mainly based on that assumed in the preliminary design. 


\section{ACCEPTANCE CRITERIA USED IN THE PRELIMINARY REFLECTOR DESIGN (HILVETY, REF. 2)}

1. Radiation damage resulting from the intense high energy (E > $1.0 \mathrm{Mev}$ ) neutron flux up to $2 \times 10^{22}$ nvt was considered acceptable, based on MTR experience.

2. Allowable thermal stress based on tests for unirradiated beryllium showed a minimum thermal stress at failure of 28,200 psi. Design value of 12,000 psi at $125 \mathrm{MW}$ was chosen for the HFIR preliminary design. It was beltived that the cooling hole surface exhibits highest stress in the reflector.

3. Sources of heat generation considered in the preliminary design calculations were prompt and capture gammas, activation gammas and betas, delayed fission product gammas, and fast neutron slowing down.

4. Water fraction affects thermal flux and reactivity. Since a $0.6 \%$ change in reactivity is equivalent to about one day of core lifetime, the reflector water content should be kept as low as possible. One of the design criteria was the requirement for the minimum reflector water content.

\section{FINITE ELEMENT MODELING OF THE PROBLEM}

A three-dimensional finite element model of 41415 elements and 64403 nodes is used to model the redesigned permanent reflector. The main differences between the redesigned geometry and the preliminary design geometry are the number of coolant holes to be used for removing the heat and the beam tube cutouts. The coolant holes are not included in the finite element geometry. Coolant holes are modeled by a distribution of heat sinks. Second order tetrahedra elements are used in the model. The number of elements and their associated number of nodes are reflected from the multiplication factor between these numbers. The model does consider the geometry of the vertical target holes as well as the horizontal beam tube cutouts but not the coolant holes through which water flows for the cooling of the permanent reflector.

The finite element calculation makes use of the 3-D heat source distribution obtained by J. C. Gehin from his results obtained by applying the Monte Carlo Code MCNP (ref. 1). Heat removal from coolant holes is approximately represented by a distribution of heat sinks. All free surfaces of the permanent reflector are assumed to follow either the heat transfer condition or the insulated condition. The geometry is built by the CAD program I-DEAS. All numerical calculations are performed by the finite element code ABAQUS.

\section{INPUTS TO THE FINITE ELEMENT MODEL}

\subsection{Reflector Geometry}

As shown in figure 1 for the lower half of the redesigned geometry, the permanent beryllium reflector is designed to have the shape of a cylindrical cylinder. It encloses the adjacent removable reflector, the control plates, and the fuel elements. The target holes are oriented along the vertical direction and the beam holes are cutouts along the midplane of the reflector. The reflector has inner diameter of 26 inches, outer diameter 43 inches and height of 24 inches. The coolant holes of 1/8 inch in diameter along the vertical or axial direction are distributed across the horizontal section of the reflector. Water passes through these holes to cool down the reflector. In the preliminary design report (ref. 2), the coolant holes are located along seven concentric circles with ninety holes per each circle. For the original design as well as this redesign geometry, the number of coolant holes has been reduced from 90 holes to 80 . holes in each row from the preliminary design configuration. The number of rows has been reduced from 7 to 4 rows. The average heat transfer coefficient on the coolant hole surface is estimated to be $5000 \mathrm{Btu} / \mathrm{hr}-\mathrm{ft}^{2}-{ }^{\circ} \mathrm{F}$. In the present redesigned reflector, the 4 rows of coolant holes have diameters $28.248,30.612$, 33.324 , and 36.438 inches, beyond which no coolant holes is believed to be required.

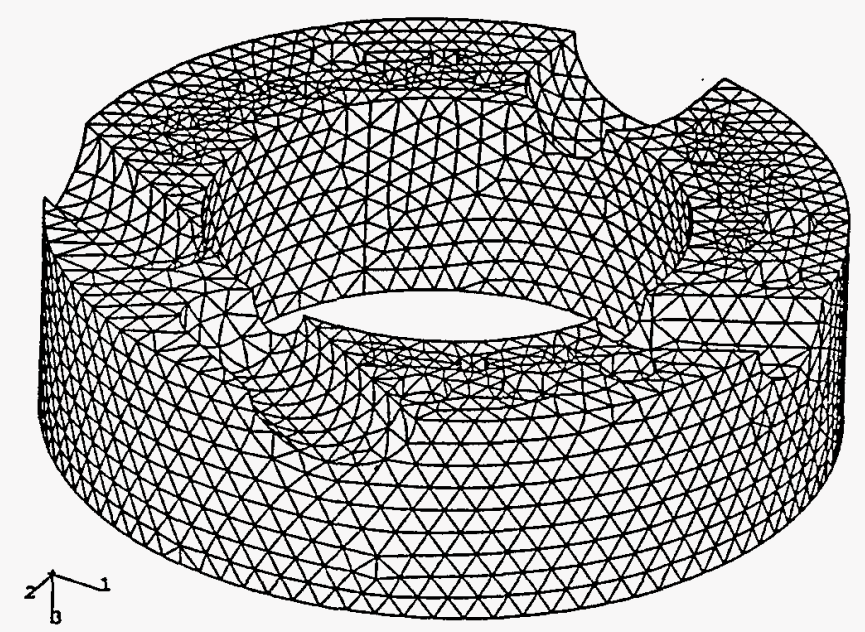

Fig 1. Finite element model for the lower half of the HFIR redesigned reflector.

\subsection{Material Properties for Beryllium}

Density

Thermal conductivity

$$
\begin{aligned}
& \gamma=1.84 \mathrm{gm} / \mathrm{cc}= \\
& 1.722 \times 10^{-4} \mathrm{lb} \mathrm{s}^{2} / \mathrm{in}^{4}{ }^{4}
\end{aligned}
$$

$$
\begin{gathered}
\mathrm{K}=5.83 \mathrm{Btu} / \mathrm{hr} \text { in }{ }^{\circ} \mathrm{F}= \\
1.7083 \text { watts } / \mathrm{in}^{\circ} \mathrm{F}
\end{gathered}
$$




$\begin{array}{ll}\text { Heat capacity } & \mathrm{C}_{\mathrm{p}}=1.2793 \text { watts } \cdot \mathrm{sec} / \mathrm{gm}^{\circ} \mathrm{F} \\ \text { Coef thermal expansion } & \alpha=9 \times 10^{-6} \mathrm{1} /{ }^{\circ} \mathrm{F} \\ \text { Modulus of elasticity } & \mathrm{E}=40 \times 10^{6} \mathrm{psi} \\ \text { Poisson's ratio } & v=0.024 \\ \text { Yield stress } & \mathrm{S}_{\mathrm{y}}=28 \times 10^{3} \mathrm{psi}\end{array}$

\subsection{Reflector Heating Rate}

The reflector heating calculations calculated recently by Gehin and the heat removal are modeled in the following interpolations:

\section{Reflector heating generated by nuclear reaction}

Two types of calculations are made to estimate the total heat load by nuclear reaction from the reactor core. The first type of calculation is a coupled neutron-photon problem that gives the neutron heating and the prompt photon heating. The prompt photon heating consists of prompt fission photons, capture photons, and inelastic scatter photons. A subsequent photononly calculation, that was the fission distribution from the coupled problem, is performed to compute the heating.

The distribution of the heat load throughout the reflector by Gehin involves both the reflector and the water heat loads for 22 and 27 inches control rod positions. The results obtained by Gehin have been compared by him to those performed by D. R. Vondy (ref. 4) in the early 1960's for the HFIR original design calculation. HFIR reflector heating rate in the original design was not based on the preliminary design heating calculation. The results of Vondy in his 1963 calculation and that of Gehin show good agreement.

\section{Analytical representation of the tabulated heat load}

The tabulated values obtained by Gehin are analytically interpolated by exponential function of the following form:

$$
y=A \cdot B^{x}
$$

where $A$ and $B$ are constants that depend on the zone regions along the axial direction of the reflector. The unit for $y$ is watts/gm per $1 \mathrm{MW}$ of reactor power. The variable $\boldsymbol{x}$ is the radial distance in centimeter from the axis of the reflector.

\begin{tabular}{c|c|c}
\hline Zone & $A$ & $B$ \\
\hline 1 & 0.258736 & 0.926595 \\
\hline 2 & 0.470268 & 0.920382 \\
\hline 3 & 0.650347 & 0.916763 \\
\hline 4 & 0.707529 & 0.915892 \\
\hline
\end{tabular}

The zoning of the reflector along its axial direction is made by Gehin to seven blocks. The heat load is symmetrically distributed across the midplane by the reflector. The above tabulated values of $A$ and $B$, therefore, only need four zone values, in which zone four corresponds to values at the midplane of the reflector.

\section{Heat removal from the reflector}

Nuclear heating of the permanent reflector is removed through cooling holes of $1 / 8$ inch diameter distributed along seven concentric circles from the axis of the reflector. Ninety holes are located evenly along each circle. The radius of each concentric circle has been tabulated. The heat is removed from the semipermanent reflector through surface heat transfer and surface grooves along which cooling water flows.

For the three-dimensional application of ABAQUS to calculate the temperature distribution, the $7 \times 90$ small heat removal holes in the permanent reflector are idealized and equivalently represented by a distribution of heat sinks. This idealization is needed because modeling by finite element method, including the coolant holes, requires a great number of elements that are beyond the capability of the machine memory. The effects of small cooling hole are later studied by using a simplified analytical solution (ref. 7).

For the three-dimensional calculation, an equivalent heat sink distribution can be obtained by the following multiplication factor for the 90 hole geometrical arrangement

$$
y=0.019067 x^{2}-0.750888 x+7.82494
$$

and for the 80 hole arrangement

$$
y=-0.00900579 x^{2}+0.198376 x-0.250667
$$

The unit of $y$ in the above equation is holes/ $/ \mathrm{in}^{2}$.

The above equations are obtained by dividing the twodimensional horizontal section of the cylinder to a distribution of areas. Each area contains only one cooling hole. The inverse of that area is represented by the above equation that gives the number of holes per unit area. The quantity $y$ that is multiplied by the rate of heat removal from one cooling hole is the rate of heat removal per unit area of the horizontal cross section of the beryllium cylinder.

The heat transfer coefficient is assumed to be

$$
h=5000 \frac{B t u}{h r \cdot f t^{2 \cdot 0} \mathrm{~F}}
$$

The cooling hole is $1 / 8$-inch in diameter and the beryllium cylinder is 24 inches long. Therefore, the rate of heat removal (Btu/hr) per unit volume $\left(\mathrm{in}^{3}\right)$ at any location in the reflector is 


$$
y \times h \times \frac{\pi}{8} \times 1 \times(T-T w) \times \frac{1}{12^{2}}
$$

where $T-T w$ is the temperature rise from water temperature $T w$ at any location in the reflector.

\subsection{Thermal Boundary Conditions}

The heat transfer boundary conditions are mainly calculated by R. B. Rothrock of RRD. Various surfaces of the permanent and semi-permanent reflectors where the cooling flow passes are assumed to follow heat transfer conditions. Several surfaces, because of the slow or stagnated fluid flow conditions, are assumed to be insulated. These surfaces are the top, bottom, and outer surfaces of the reflector. A list of the heat transfer coefficients of the surfaces along which water flows rapidly are listed in the following:

\section{Permanent reflector coolant holes (1/8-inch holes)}

These coolant holes are designed and arranged throughout the reflector to properly cool down the reflector heating (ref. 2, page 17). For a 10-psid pressure drop across the permanent reflector upper and lower surfaces, Hilvety estimated a hole water velocity of approximately $15 \mathrm{ft} / \mathrm{sec}$ that led to the heat transfer film coefficient for the $1 / 8$-inch hole

$$
h=5000 \frac{B T U}{h r \cdot t^{2 \cdot{ }^{\circ} F}} \text {. }
$$

It is noted that the $1 / 8$-inch coolant holes in the permanent reflector has pressure drop of $10 \mathrm{psid}$ and the total length of 24 inches. The coolant groves on the outer surface of the semipermanent reflector, and the clearance between the CRAPS and the permanent reflector all have the same pressure drop and the same length of 24 inches. Therefore, their respective flow velocities and heat transfer coefficients are related by their hydraulic diameters developed below.

\section{Permanent reflector inner surface, adjacent to semi-} permanent reflector

The semi-permanent reflector has 0.125 inch diameter semicircular grooves cut into its outer diameter to provide cooling flow between the semi-permanent reflector and the permanent reflector.

$$
\begin{aligned}
D_{H} & =\frac{4 A}{P} \\
& =\frac{1 / 2 \pi D^{2}}{1 / 2 \pi D+D}=\left(\frac{1}{1+\frac{2}{\pi}}\right)(D) \\
& =(0.61)(1 / 8)=0.07638 \text { inch }
\end{aligned}
$$

This semi-circular groove has the hydraulic diameterwhere $A$ is the area, $P$ is the perimeter of the groove, and $D$ is the regular cooling hole diameter.

Assume that the pressure drop $\Delta \mathrm{P}$ across the coolant channels is related to their hydraulic diameter (ref. 6, p. 503) by the following relation

$$
\frac{\Delta P}{V^{2} / D}=\text { friction function }
$$

that is a slowly varying function of Reynolds number.

It follows that

$$
\frac{V_{1}^{2}}{D_{1}}=\frac{V_{0}^{2}}{D_{0}} \text { or } \frac{V_{1}}{V_{0}}=\sqrt{\frac{D_{1}}{D_{0}}} .
$$

Also, the heat transfer coefficient $h$ is related to hydraulic diameter and velocity by the expression

$$
\frac{h D}{K}=\text { constant }\left(\frac{V \rho D}{\mu}\right)^{0.8}\left(\frac{\mu C_{P}}{K}\right)^{0.4}
$$

For constant material properties in different coolant channels, the following simplification holds

$$
\frac{h_{1} D_{1}}{h_{0} D_{0}}=\left(\frac{V_{1} D_{1}}{V_{0} D_{0}}\right)^{0.8} \text { or } \frac{h_{1}}{h_{0}}=\frac{D_{0}}{D_{1}}\left(\frac{V_{1} D_{1}}{V_{0} D_{0}}\right)^{0.8} \text {. }
$$

From an earlier result that

$$
\frac{V_{1}}{V_{0}}=\left(\frac{D_{1}}{D_{0}}\right)^{0.5}
$$

it implies

$$
\begin{aligned}
\frac{h_{1}}{h_{0}} & =\frac{D_{0}}{D_{1}}\left[\left(\frac{D_{1}}{D_{0}}\right)^{0.5}\left(\frac{D_{1}}{D_{0}}\right)\right]^{0.8} \\
& =\left(\frac{D_{1}}{D_{0}}\right)^{0.2}
\end{aligned}
$$

From Hilverty's calculation (ref. 2), the permanent reflector $1 / 8$ inch coolant hole has the heat transfer coefficient as

$$
h=5000 \frac{B t u}{h r \cdot f t^{2 \cdot 0} \mathrm{~F}}
$$

with hydraulic diameter

$$
D=0.125 \text { inch }
$$


The heat transfer coefficient $h_{1}$ for the semi-circular coolant channel along the outer edge of the semi-permanent reflector is

$$
\begin{aligned}
h_{1} & =5000\left(\frac{0.61 \times 0.125}{0.125}\right)^{0.2} \\
& =5000(0.906)=4500 \frac{B t u}{h r f t^{2 .}{ }^{\circ} F}
\end{aligned}
$$

The 0.125 -inch wide grooves are spaced $4^{\circ} 30^{\prime}$ apart on a radius of 13.125 inch, or

$$
\frac{4.5}{360} \times 2 \pi(13.125)=1.03 \text { inch spacing. }
$$

If we ignore the heat transfer across the contracting surfaces of the permanent and semi-permanent reflectors and average the $45000 \mathrm{Btu}\left(\mathrm{hr} \mathrm{ft}^{2}{ }^{\circ} \mathrm{F}\right)$ coefficient over the space between coolant grooves, then an average heat transfer coefficient would be

$$
h_{\text {avg }}=\frac{0.125}{1.03}(4500)=550 \frac{B t u}{h r \cdot t^{2 \cdot \circ} \mathrm{F}}
$$

\section{Inner and outer surfaces of the semi-permanent reflector}

Heat transfer coefficient for the outer surface of the semipermanent reflector is the same as that for the inner surface of the permanent reflector. For the inner surface of the semipermanent reflector, the heat transfer condition is provided by the semi-circular coolant channels of the removable reflector. The spacing of these channels are $21 / 2$ degrees apart, instead of $41 / 2$ degrees for its outer surface channels.

Recall that the heat transfer coefficient for the inner surface of the permanent reflector has been calculated earlier. After interpolation, we obtain the heat transfer coefficient of the inner surface of the semi-permanent reflector as

$$
h_{2}=550 \times \frac{4.5}{2.5}=1000 \frac{B t u}{h r-f t^{2 . \circ} \mathrm{F}}
$$

\section{Permanent reflector to CRAPs}

The CRAPs have smooth surface next to the permanent reflector inner surface with no groove, and are spaced 1/16-inches from the reflector by spacers at top and bottom. This is equivalent to a hydraulic diameter of $1 / 8$ inch that is same as that of the internal coolant hole. Therefore, the heat transfer coefficient is approximately the same as that for the internal coolant hole of $5000 \mathrm{Btw}\left(\mathrm{hr} \cdot \mathrm{ft}^{2} \cdot{ }^{\circ} \mathrm{F}\right)$.

\section{Heat removal through VXF plug/liner gaps}

The standard VXF plugs include provisions for coolant flowing through a 0.05 -inch gap between the plug and the inner surface of the liner. The total flow to all 22 VXFs is given in the SAR as $365 \mathrm{gpm}$. The total flow area through 0.05 -inch gaps including VXF-7 is

- Small VXFs $-16 \times \pi \times 1.584 \times 0.05=3.98 \mathrm{in}^{2}$

- Large VXFs $-6 \times \pi \times 2.834 \times 0.05=2.67 \mathrm{in}^{2}$

with a total of $6.65 \mathrm{in}^{2}$.

The average velocity through the $6.65 \mathrm{in}^{2}$ area at $365 \mathrm{gpm}$ is

$$
\begin{aligned}
V_{\text {avg }}= & 365 \frac{\mathrm{gal}}{\mathrm{min}} \times \frac{1}{6.65 \mathrm{in}^{2}} \times \frac{1 \mathrm{~min}}{60 \mathrm{sec}} \\
& \times \frac{1 \mathrm{ft}^{3}}{7.5 \mathrm{gal}} \times \frac{144 \mathrm{in}^{2}}{1 \mathrm{ft}^{2}}=17.56 \mathrm{ft} / \mathrm{sec}
\end{aligned}
$$

Equivalent hydraulic diameter $=$

$$
\frac{4 \pi \times 1.584 \times 0.05}{\pi \times 1.584 \times 2}=2(0.05)=0.10 \text { inch }
$$

An application of

$$
\frac{h_{1} D_{1}}{K} \times \frac{K}{h_{0} D_{0}}=\left(\frac{V_{1} \rho D_{1}}{\mu_{1}} \times \frac{\mu_{0}}{V_{o} \rho D_{o}}\right)^{0.8}
$$

will lead to the result

$$
\begin{aligned}
h_{1} & =h_{0}\left(\frac{D_{0}}{D_{1}}\right)^{0.2}\left(\frac{V_{1}}{V_{0}}\right)^{0.8} \\
& =5000\left(\frac{0.125}{0.100}\right)^{0.2}\left(\frac{17.6}{15}\right)^{0.8} \\
& =6000 \frac{B t u}{h_{r f t^{2 .}{ }^{\circ} \mathrm{F}}}
\end{aligned}
$$

\section{Heat removal from beam tube cutouts}

Cooling of the reflector interior surface along the beam tube cutouts is provided by:

1. For the hemispherical part of the beam tube, a 0.040-inch gap between beam tube nose and cutout inner diameter which allows coolant to circulate around the spherical cutout from $1 / 8$-in inlet holes on top of the tube and exist through the $1 / 8$-inch holes at bottom of the beam tube.

2. For the cylindrical part of the beam tube, $3 / 8$-inch-wide $x$ 0.050 -in-deep grooves cut in the beam hole liner to carry cooling water from inlet $1 / 8$-inch holes above the beam tube to outlet holes below the beam tube.

Because the nose of the tube is located at the highest heating region and subject to greatest gradient, the heat transfer 
coefficient for (1) above will be estimated, and assumed to apply to other regions as well. Dimensions for $\mathrm{HB}-2$ will be used for this purpose, since it has the largest region close to the reactor core. For part (2), heating is relatively low, an approximate use of the heat transfer coefficient of the vertical coolant holes will be used.

The heat transfer coefficient at the hemisphericalrt of HB-2 cutout is calculated as follows: The flow passing the $1 / 8$-inch vertical cooling holes that enter the HB-2 liner is diverted around an average distance of one quarter of the HB-2 tube circumference; i.e., $\pi D / 4=\pi / 4 \times(9.33)=7.33$ inches, and the corresponding length of the $1 / 8$-inch holes are $24-7.33=16.7$ inches.

The hydraulic diameter of the gap is

$$
D=\frac{4 \times \text { length } \times 0.04}{2(\text { length }+0.04)}=0.08 \text { inch }
$$

for length of $15 / 16$ inch and the flow area is $0.040 \times 15 / 16=$ $0.375 \mathrm{in}^{2}$ per side.

The flow area of the half of the seven holes that intercept the $\mathrm{HB}-2$ would be

$$
(3.5) \times \frac{\pi}{4}(0.125)^{2}=0.043 \mathrm{in}^{2}
$$

If we set $V_{1}$ to be the velocity of water passing through the vertical 1/8-inch cooling holes feeding the liner, then the velocity in the 0.040 -inch gap is

$$
V_{\text {gap }}=\frac{0.043}{0.0375} V_{1}
$$

and, therefore,

- L/D for water path thorough holes $=\frac{16.7}{0.125}=134$

- L/D for water path through gap $=\frac{7.33}{0.080}=92$

The total change of pressure for flow through vertical holes and around the gap must equal to the same $\Delta \mathrm{P}$ across the reflector as $15 \mathrm{f} / \mathrm{sec}$ flow through one 1/8-inch hole of 24 inches length. Hence, canceling common factors and assuming the friction factors are all the same, the pressure drops are related by

$$
{ }_{0}^{2}\left(\frac{24}{0.125}\right)=V_{1}^{2}\left(\frac{16.7}{0.125}\right)+\left(\frac{0.043}{0.0375} V_{1}\right)^{2}\left(\frac{733}{0.080}\right)
$$

where $V_{0}$ is the regular vertical $1 / 8$-inch hole velocity and $V_{1}$ is the velocity for the vertical holes that are cutout by HB-2. The above equation reduces to

$$
\begin{aligned}
V_{0}^{2}(192) & =V_{1}^{2}(134+1.315+91.6)=V_{1}^{2}(254) \\
V_{1} & =0.87 V_{0}=13 f t / \mathrm{sec}
\end{aligned}
$$

and

$$
V_{1}\left(\frac{0.043}{0.375}\right)=\text { velocity around gap }=15 \mathrm{ft} / \mathrm{sec} .
$$

Since the velocity around the nose is approximately equal to the velocity in the regular cooling holes for which $h=5000$ $\mathrm{Btu} /\left(\mathrm{hr} \cdot \mathrm{ft}^{2} \cdot{ }^{\circ} \mathrm{F}\right)$, the heat transfer coefficient for the nose region can be obtained according to the differences in their hydraulic diameters, that are 0.08 inch and 0.125 inch. For constant velocity, the heat transfer coefficient is inversely proportional to $\mathrm{D}^{0.2}$ according to

$$
\frac{h D}{K}=\text { constant }\left(\frac{V \rho D}{\mu}\right)^{0.8}\left(\frac{\mu C_{P}}{K}\right)^{0.4} .
$$

The heat transfer coefficient for the spherical surface of $\mathrm{HB}-2$ is

$$
h=5000\left(\frac{0.125}{0.080}\right)^{0.2}=5500 \frac{B t u}{h r-f t^{2.0} F}
$$

\section{CALCULATIONS AND ANALYSIS}

In the three-dimensional finite element model, all target holes and the beam tube holes are modeled. The small coolant holes are not included in the finite element model. The coolant hole stresses are calculated by applying the analytical formulas (refs. 5 and 7).

\subsection{Temperature and Thermal Stress Distributions for the Permanent Reflector}

It has been described in earlier sections how the heat rate and heat removal are modeled. Three-dimensional heat conduction equation is used to calculate the transient temperature distribution,

$$
K\left(\frac{\partial^{2}}{\partial x^{2}}+\frac{\partial^{2}}{\partial y^{2}}+\frac{\partial^{2}}{\partial z^{2}}\right) T=\gamma C_{p} \frac{\partial T}{\partial t}-Q
$$

Where $Q$ is the sum of the radiation heating sources and the heat removal source, $K$ is the heat conduction coefficient, and $\gamma c_{p}$ is the heat capacity per unit volume.

In the finite element calculation, the heat source is applied instantly and the transient temperature distribution is obtained. The temperature reaches its equilibrium state in the calculation at approximately 50 seconds. The temperature distribution at 50 seconds is obtained and reaches approximately the steady state. The maximum temperature increase is approximately $26^{\circ} \mathrm{F}$ that 
appears along the midplane close to the inner surface of the permanent reflector. Close to the outer surface, the equilibrium temperature increase is approximately $10^{\circ} \mathrm{F}$. Since the heat removal is assumed by a distribution of heat sinks, the temperature distribution on the two-dimensional cross section or the reflector is relatively smooth.

The corresponding thermal stress at the equilibrium temperature is also obtained. It is expressed in terms of the Tresca stress that is the difference of the maximum normal stresses. The maximum Tresca stress is approximately $9.6 \mathrm{ksi}$ at the surface colse to the beam tube cutouts. The tensile stress of approximately $2.5 \mathrm{ksi}$ appears along the midplane at the outer surface of the reflector. Tensile stress will promote cracking. This will have a pronounced effect when the beryllium is embrittled after years of radiation and helium gas attack.

\subsection{Simplified Stress Estimate Along the Surface of the Coolant Hole}

Coolant water holes are distributed throughout the permanent reflector. Preliminary design calculation by Neil Hilvety indicated that 90 holes are distributed evenly along each radius of the cross-sectional area of the reflector. There are seven radial distances on which the holes are distributed. The hole diameter is $1 / 8$ inch.

In his report, the heat transfer coefficient is $5000 \mathrm{Btu} /\left(\mathrm{hr} \cdot \mathrm{ft}^{2} \cdot{ }^{\circ} \mathrm{F}\right)$. A total of $1.7 \mathrm{MW}$ of heat power is removed from the reflector. He estimated that the surface thermal stress is approximately 11 ksi and a rise of temperature for the cooling water passing through the hole is $30^{\circ} \mathrm{F}$ under the condition that HFIR is operated at $125 \mathrm{MW}$ power. His heating rate is estimated as 10 watts/gram.

The coolant hole stress of 11 ksi was calculated by Hilvety, but he did not show the detailed derivation. The finite element solution carried out in this report can not calculate the cooling hole stress. This stress, however, provides the possible critical stress anywhere in the reflector. Hilvety's temperature and stress distributions are to be confirmed in the following. Both the temperature drop and the coolant hole stress calculations for a hollow cylinder are based on the standard solutions from a reactor design book (ref. 7). The coolant hole stress under the redesigned heating and geometry is also calculated.

The analytical expression for the temperature drop for the hollow cylinder with internal heat source and insulated at the outer boundary according to reference 5.0 is

$$
\Delta T=\frac{H a^{2}}{4 k}\left(1-\frac{b^{2}}{a^{2}}\left(1+2 b^{2} \log \frac{a}{b}\right)\right)
$$

where $a$ and $b$ are assumed to be the inner and outer radii of the cylinder, respectively. In the above equation, $H$ is the heat source and $k$ is the heat conductivity of beryllium. The logarithmic function is understood to be the natural logarithm. The circumferential stress along the coolant hole surface is

$$
\sigma_{\theta}(r=a)=\frac{\alpha E H}{16(1-v) k}\left(\frac{8 b^{4}}{b^{2}-a^{2}} \log \frac{b}{a}-6 b^{2}+2 a^{2}\right)
$$

and the axial stress is equal to the circumferential stress at the inner surface of the hollow cylinder.

\subsubsection{Temperature and Thermal Stress Distributions for the Permanent Reflector in the Preliminary Design Calculation}

In Hilvety's report the outer radius $b$ is assumed to be 0.5 inch and the inner radius is $1 / 16$ inch. The outer radius was obtained by Hilvety by equating the energy input as the reflector was subdivided into triangular cells. Each cell contained the coolant hole at its center and the area was made equivalent to a circular area. For $125 \mathrm{MW}$ reactor power, $H$ is 10 watts/gram.

These numerical values are substituted in to the above equations. The temperature drop is

$$
\begin{aligned}
\Delta T & =0.0173 H \times\left(1-8^{2}\left(1+2 \log \left(\frac{1}{8}\right)\right)\right) \\
& =35.5^{\circ} \mathrm{F}
\end{aligned}
$$

and the coolant hole surface stress is

$$
\begin{aligned}
& \sigma_{0}(r=a)=\frac{9 \times 10^{-6} \times 40 \times 10^{6} \times 0.0173 H}{4(1-0.024)} \\
& \left(\frac{8(8)^{4}}{8^{2}-1} \log (8)-6(8)^{2}+2\right)=11.1 \times 10^{3} p s i
\end{aligned}
$$

that is approximately the value obtained by Hilvety (ref. 5.4).

\subsubsection{Temperature and Thermal Stress Distributions for the Permanent Reflector in the Redesigned Calculations}

In the present redesigned reflector, the number of coolant holes has been reduced in each row from 90 to 80 . The number of rows has been reduced from 7 to 4 rows with diameters 28.248 , $30.612,33.324$, and 36.438 inches beyond which no coolant holes is believed to be required. The equivalent energy method is used to determine the radius of the outer diameter of the hollow cylinder. For the first row of holes where the maximum amount of heat is removed square cells are assumed to absorb the same amount of energy as the cylinder with outer radius $b$ that satisfy that following relation

$$
\left(\frac{28.248 \times \pi}{80}\right)^{2}=\pi \times b^{2}
$$

From which $b$ is 0.626 inches. The ratio $b / a$ is 10 . New heating rate calculation for the power density $H$ is 4 watts per gram of beryllium at $100 \mathrm{MW}$ reactor power. 
At $125 \mathrm{MW}$ reactor power the power density $H$ is 5 watts per gram. The temperature drop across the hollow cylinder is

$$
\begin{aligned}
\Delta T & =0.0173 H \times\left(1-10^{2}\left(1+2 \log \left(\frac{1}{10}\right)\right)\right) \\
& =31.3^{\circ} \mathrm{F}
\end{aligned}
$$

and the coolant hole surface stress is

$$
\begin{aligned}
& \sigma_{\theta}(r=a)=\frac{9 \times 10^{-6} \times 40 \times 10^{6} \times 0.0173 H}{4(1-0.024)} \\
& \left(\frac{8(10)^{4}}{10^{2}-1} \log (10)-6(10)^{2}+2\right)=10.07 \times 10^{3} p s i
\end{aligned}
$$

that is also approximately the value obtained by Hilvety.

\section{RESULTS AND DISCUSSION}

The main objective of this report is to apply the finite element method to evaluate the stress distribution of the redesigned HFIR beryllium reflector. The maximum stress obtained from this calculation needs to be bounded by the allowable stress of $12 \mathrm{ksi}$ for beryllium.

This finite element solution does show detailed stress distribution of the reflector including horizontal beam tube cutouts and target hole geometry. It is a detailed stress distribution except stresses along the surfaces of the coolant holes. The coolant hole stress was originally calculated by Hilvety in the preliminary HFIR design report and was estimated to be $11 \mathrm{ksi}$ (ref. 2). The finite element solution for the detailed reflector shape including new horizontal beam tube cutouts and the target holes shows that the maximum stress appears at the tip of the HB-2 cutout. The maximum Tresca stress is approximately $9.6 \mathrm{ksi}$, not including the coolant hole surface stress.

\section{CONCLUSIONS}

Detailed finite element calculations are made to estimate the redesigned reflector temperature and thermal stress that are generated as a result of nuclear reaction. The maximum finite element stress appears at areas at the beam tube cutouts. The preliminary design temperature and stress calculations have also been confirmed in this report. These preliminary results were based on a rough estimate by applying a circular cylinder thermal stress solution in elasticity (ref. 7). No refined calculation was possible at that time for estimating the detailed stress distribution of the reflector. The temperature and thermal stress around the HB-2 shows a slight increase in values but they are still less than the allowable stress based on the preliminary design allowable stress of $12 \mathrm{ksi}$.

\section{REFERENCES}

1. J. F. Briesmeisted, editor, MCNP - A General Monte Carlo $N$-Particle Transport Code, Version 4A, LA-12625-M, 1993

2. C. E. Hilvety, HFIR Beryllium Reflector Preliminary Design Report, ORNL - CF - 61-2-81, February 21, 1961

3. Taylor Lyman, et al, Metals Handbook, 8 th edition, vol. 1, Properties and Selection of Metals, published by American Society for Metals, Metal Park, Novelty, Ohio, 1961, pp. 1198-1199

4. D. R. Vondy, Gamma Rays and Neutron Heat Generation in the HFIR, ORNL/CF 63-2-52, February 21, 1963

5. S. Timoshenko and J. N. Goodier, Theory of Elasticity, 3rd edition, McGraw-Hill, New York, 1970, pp. 448-449

6. H. Schlichting, Boundary Layer Theory, 2nd edition, McGraw-Hill, New York, 1960, p. 503

7. C. F.Bonilla, editor, Nuclear Engineering, McGraw-Hill, New York, 1957, p. 381 and p. 568 
M98005643

||||||||||||||||||||||||||||||||||||||||||||||||||||||

$\frac{\text { Report Number (14) ORNL/CP--98/89 }}{\text { CONF-980708-- }}$

Publ. Date (11) 199804

Sponsor Code (18) DOE/ER, XF

UC Category (19) UC-400, DOE/ER 